\title{
The Silent Diffusion of Sticky Costs in the HoReCa Industry
}

Wolfram Irsa

FH Burgenland - International Joint Cross-Border PhD Programme in International Economic Relations and Management, Austria

\section{Abstract}

Sticky costs materialize when costs increase more with rising an activity than they decrease with falling of the very same amount of the activity. Over time a silent diffusion of sticky costs can be observed in the HoReCa (HOtel/REstaurant/CAtering) industry. In sticky costs literature the cost behaviour is evaluated by correlating the current growth in Selling, General and Administrative costs - often referred to overhead - with current revenue growth. Recently, research identified several attributes affecting the hysteresis (Greek: remaining even if the cause is no longer there) of cost. Managerial oversight, external regulatory conditions and company culture are an example of such attributes. First insights indicate that the dependence of a system on its history is the driving force to determine the severance of cost stickiness. It depends for different sizes of corporations on the corporate governance model and on the successful variabilization of costs. This paper presents the most important attributes affecting sticky cost. Further, the various implementations in real managerial decision-making processes in the HoReCa industry are described on the example of the region of Opatija, Croatia. A qualitative research using ATLAS.ti as Computer Assisted Qualitative Data Analysis Software (CAQDAS) is the chosen approach for unveiling the desired findings.

Keywords: cost behaviour, overhead cost management, qualitative research, VUCA (volatility, uncertainty, complexity and ambiguity)

JEL classification: D22, G41, M14

Acknowledgments: I thank Professor Zavrl for the opportunity to participate in the programme which leads me to participate at the Entrenova 2019. Additionally, I wish to thank the two anonymous reviewers who gave invaluable feedback for improvement.

\section{Introduction}

The HoReCa (HOtel/REstaurant/CAtering) industry in the region of Opatija is characterized through superior service, history-rich background, and breath-taking beauty of the Istrian coast. These ingredients guarantee an almost certain economic success. Nevertheless, the region competes with other top-notch location around the globe to attract the affluent tourist for spending time and money.

Private business owners of HoReCa facilities struggle to make ends meet by fulfilling the ever-increasing demands of spoiled tourists as well as the steadily growing burden of regulations. Ofttimes, the cost pressure accounts for explanations of deferred investments. Although, a more detailed look is needed to understand the specifics of the cost situation.

The purpose of this research is to find out how the increase of business activity (often expressed as revenue in Euro) is accompanied by an increase of long-term fixed costs 
(also expressed in Euro). A qualitative research using the well tested methodology of Grounded Theory unveils the driving forces of these dynamics and how the business owners deal with the situation. Cerovic et al. (2014) points out that the region of Opatija is stuck by missing innovation. On the other side Slivar $(2016, \mathrm{p}$. 45) refers to the attitude of "Innovations are our priority" that enables new touristic products in the region. This contrast indicates a compelling cause and deserves detailed exploration.

It turns out that this contradiction - depending on the point of view - has a root cause called sticky costs. The term has been coined in the financial controlling community (Sorros et al., 2013) to describe the phenomenon that once accrued costs are hard to scale back even if the reason (once used) to justify them no longer exists. Plenty of empirical data (Cheung, 2018) confirm this fact. Although, what remains unanswered is the question: How do business leaders in the HoReCa industry in Opatija deal with sticky costs? The research goal is a qualitative answer to this research question. As it is an inductive approach an abductive research hypothesis is formulated, which could be validated/falsified in an additional research effort.

Subsequently in this paper, the methodology, the results, the discussion, and the conclusion embrace the subject matter.

\section{Methodology}

The methodology of Grounded Theory helps to seek and find a mid-level theory which explains real-life situations by connecting it with the evidence of the observation. As a result, the theory delivers consistency with the empirical data (Orlikowski, 1993; Eisenhardt, 1989). The data collection, the rationale of the coding, the integration of categories, the abstraction from the original data and finally the construction of the theory is led by the methodology as it emerges the theory which is grounded on the evidence. Hughes and Wood-Harper (1999) indicate that the main application areas of the Grounded Theory methodology are social science in the health care system. Next to them, performed by many others, often in the field of medical or nursing related areas (e.g. experiences with chronic illness) (Charmaz, 1980), homecoming (Hall, 1992), and the management of a hazardous pregnancy (Corbin, 1992). Additionally, a lot of work has been done concerning the guidance how to apply the Grounded Theory methodology. Most notable amongst them include Martin and Turner (1986); Strauss and Corbin (1998); Charmaz (2008); Jones and Alony (2011). Recently, Grounded Theory even became popular for qualitative topics in business management as it allows a fresh view on quantitatively already well-tested explanations (Boadu et al., 2015).

The result is the detected theory grounded by the evidence to the specific phenomenon, which is in the particular case the handling of sticky costs. It iterates permanently by challenging the concepts with the data and contrariwise. The comparative nature of the approach happens constantly by scrutinizing the evidence. This develops the conceptual structure next to the overall scope of emerging a mid-level theory to explain the phenomena. The paper's argument should be built on concepts, categories, or other ideas. The methods employed needs the appropriate application of a real-life application/phenomenon.

ATLAS.ti is a computer-assisted qualitative data analysis software that supports the organization of qualitative data. It facilitates several layers of coding, the aggregation to concepts and categories which includes the core category. 
Figure 1

Grounded Theory Data Analysis Steps
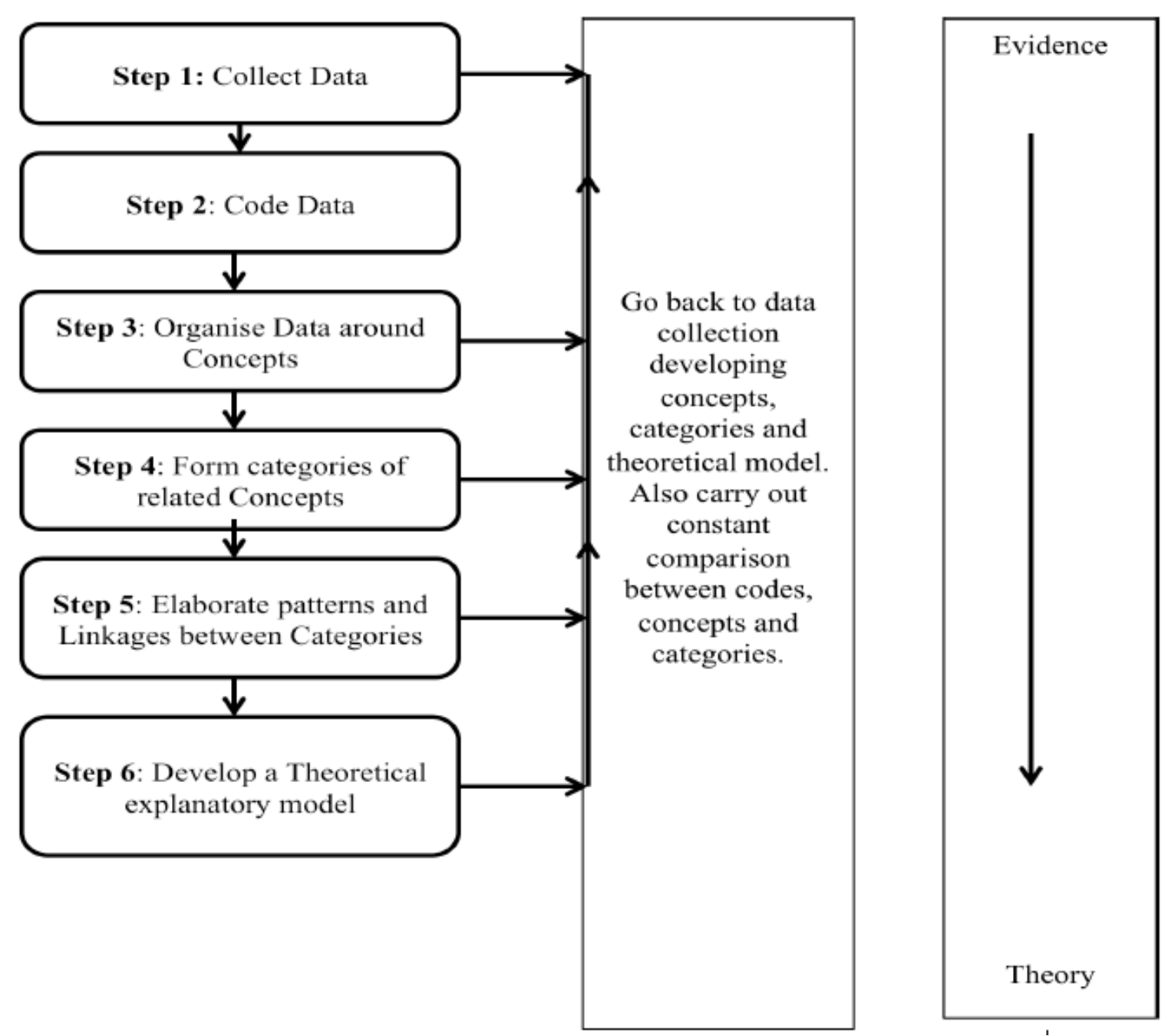

Source: (O'Hagan et al., 2015, pp. 8)

Figure 1 depicts the six steps to develop a theoretical explanatory model, in a broader sense a theory grounded on the evidence. ATLAS.ti supports the iteration of the process.

The author carried out twelve qualitative interviews with business leaders in Opatija, mainly directors of great resorts. An interview guideline (not displayed in detail for sake of brevity) helped to perform consistent and comparable conversations. Already after several interviews it turned out that the topic of sticky costs circulates around VUCA, which stands for volatility, uncertainty, complexity, and ambiguity. Nevertheless, it has been worthwhile to look deeper, which is explained in results.

\section{Results}

The interviews are the basis for the results. It turned out that after eight interviews no substantial new information was brought forward anymore. Therefore, it is fair to say even with the small number of total interviews - that saturation, which is a critical success factor for qualitative research, has been achieved. 
Figure 2

Dynamics of Selling General and Administrative costs and Revenue

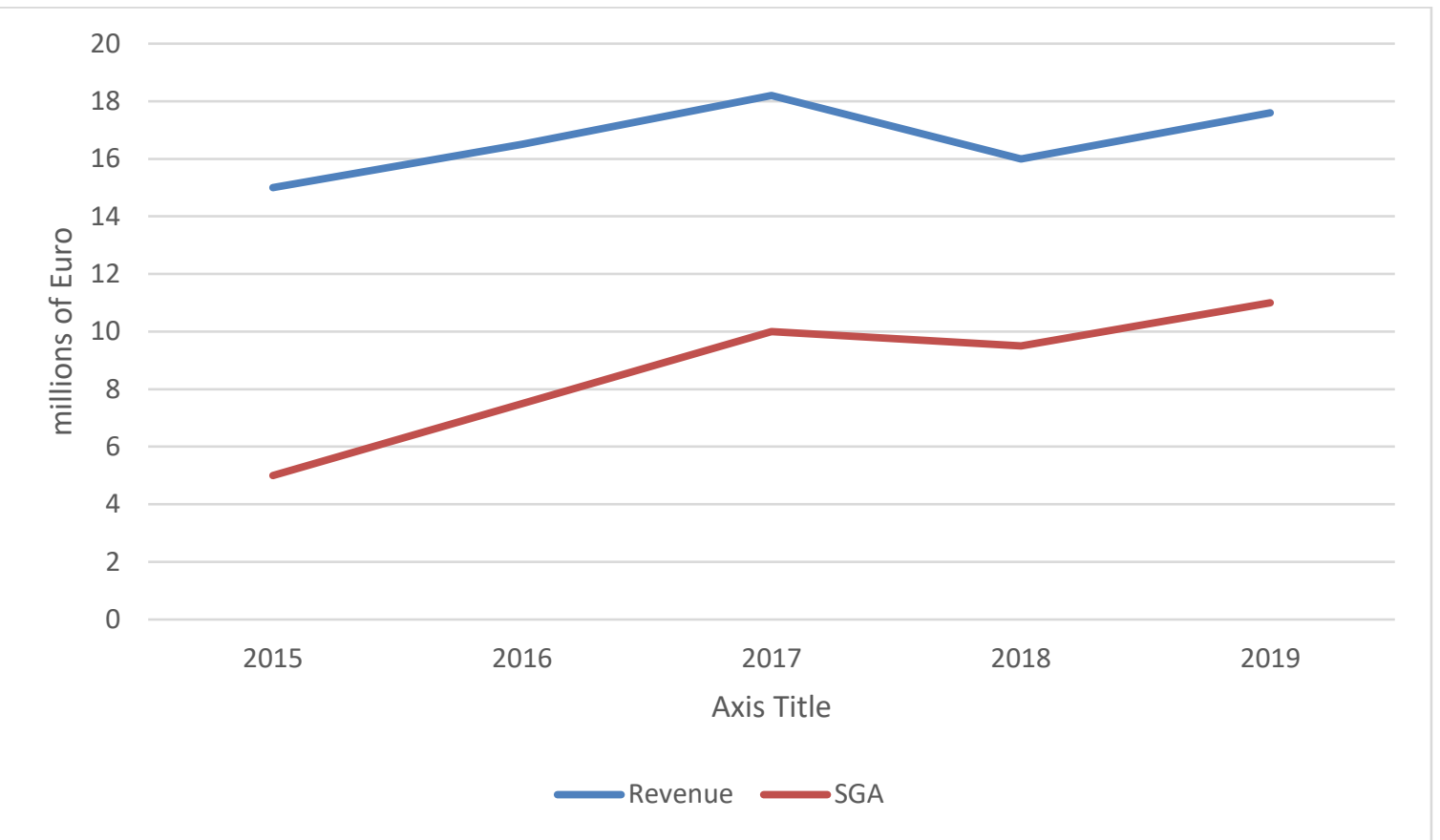

Source: Authors' illustration

Figure 2 represents the number of an anonymous HoReCa facility in Opatija and contains two lines, one - the upper one - is revenue, measured in millions of Euro. The lower one shows the costs of Selling, General and Administration (SGA), expressed in millions of Euro as well. The SGA increases faster than the revenue in the first two years. In the third year - between 2017 and 2018 - the revenue declines sharply whereas SGA diminishes only gradually. Then, in the following year the raising revenue is mirrored by an increase of SGA, almost in parallel. It seems whatever the business is doing, one thing is for sure: costs tend to remain stubbornly sticky on the organization regardless of the level of the business activity. Over a four-year horizon a silent but dramatic increase of sticky costs by $120 \%$ took place (whereas revenue increased by $17 \%)$. These numbers are used as an example to drill deeper.

The transcription and coding of the interviews unveiled concepts that were subsequently condensed to categories, sub-core categories and finally to one core category. Open coding delivered the concepts (including the properties) by analysing the text line-by-line and word-by-word. Axial coding related the categories to each other, specified the properties and reassembled the data to give coherence to the emerging findings. Selective coding, finally, identifies the core category, relates it systematically to the other categories, validates the relationships, and fills in categories that need further refinement. 
Table 1

Concept - Categories - Core Category

\begin{tabular}{|c|c|c|c|}
\hline Core Category & Dependence on past $p$ & erformance & \\
\hline Sub-core Categories & $\begin{array}{l}\text { Corporate } \\
\text { governance model }\end{array}$ & $\begin{array}{l}\text { Variablization } \\
\text { of Costs }\end{array}$ & \\
\hline Categories & $\begin{array}{l}\text { External regulatory } \\
\text { conditions }\end{array}$ & $\begin{array}{l}\text { Managerial } \\
\text { sight }\end{array}$ & Company culture \\
\hline Concepts & $\begin{array}{l}\text { Heritage } \\
\text { Appearance } \\
\text { National laws } \\
\text { EU conformity } \\
\text { GRI (Global Reporting } \\
\text { Initiative) } \\
\text { IFRS (International } \\
\text { Financial Reporting } \\
\text { Standards) }\end{array}$ & $\begin{array}{l}\text { Transparency } \\
\text { Objectivity } \\
\text { Sustainability } \\
\text { Long-term view } \\
\text { Mid-term view } \\
\text { Short-term view } \\
\text { Short-term contracts } \\
\text { Cost driver } \\
\text { social media }\end{array}$ & $\begin{array}{l}\text { Resources } \\
\text { Leadership style } \\
\text { Processes } \\
\text { Organization } \\
\text { Start-up mentality } \\
\text { Maturity of } \\
\text { organization } \\
\text { Hire-and-Fire } \\
\text { Development } \\
\text { Training } \\
\text { Sourcing (buying vs } \\
\text { making) }\end{array}$ \\
\hline
\end{tabular}

Note: Result - The concepts are the qualitative aggregation of the interviews Source: Authors' work

Table 1 delivers the core category of the study, which is dependence on past performance. It has manifold meanings. The corporate governance model (once defined how to run the organization) and the successful variablization of costs (often at the expense of long-term success) are the corresponding sub-core categories. The induction of the found concepts condensed to three categories: (1) external regulatory conditions, (2) managerial oversight, and (3) company culture. Especially the first two categories are associated with a silence, hence gradually increase of SGA. The model implies direct links between the categories and is not explicitly depicted in the paper. It leads to the research hypothesis: Sticky costs are driven by the dependence on past performance.

\section{Discussion}

The research question states: How do business leaders in the HoReCa industry in Opatija deal with sticky costs? The answer depends on the past performance of the enterprise. The external regulatory conditions are very hard to influence. The most leverage how to deal with sticky costs lies in the variabilization of costs and in the culture of the company. Three hands-on implications need attention: (1) short-term contracts, (2) buying instead making, and (3) using social media for spot business.

Let's discuss the first, the application of short-term contracts (e.g. for employment, services). It belongs to two categories: managerial oversight and company culture. Short-term contracts are the most obvious solution to reduce the dependency on long-term costs. However, it represents a hire-and-fire mentality, that is questionable. As an example, serves the employment of seasonal staff.

The second - using preferably buying instead making - is consistent with other industries (Krol, 2017). It addresses the sourcing strategy in the category company culture. It assumes that the self-making of products and services needs long-term commitments to staff specialists. As an example, serves buying services from an agency, which seems easy. But there is a drawback. - It is a matter of quality. Customer-tailored quality can be much better controlled by developing it in-house. 
Using agencies means extensive legal and quality assurance efforts that result ironically - in higher sticky costs.

The third - using social media for spot business - is a compelling response. It belongs to managerial oversight and it is bi-directional: customer-oriented and supplieroriented. As an example, serves the internet where online hospitality services like AirBedandBreakfast.com are used to offer free capacity to a world-wide audience/customer. But on the other side the internet enables the participation in online supplier auctions to take advantage on temporarily available buying opportunities, so called spot business.

An additional aspect delivers the view of a director of a mid-size hotel who recommends using sticky costs to their benefit. He recommends that long-term contracts with employees guarantees stability for the organization, which enables crucially needed service quality. During off-season the hardly fully occupied employees undergo trainings and help to prepare the season. Nevertheless, he said that the model works still best in theory. Empirically, the human resources department applies during the off-season a part-time model but is eager to keep the staff. Others would lay-off the people.

\section{Conclusion}

In this paper the research delivered explanations how HoReCa business owners in Opatija deal with sticky costs. Three categories of explanations were developed. For the sake of brevity just the major elements have been described.

Compared with other qualitative studies, it is recommended to benchmark the study against other regions in the world. Unfortunately, there is hardly any data available.

The practical implications are that the chosen corporate governance model as well as the variablization of costs are the best response. Many steps between the categories could be explored/elaborated. A quantitative verification would bring a holistic clarification on the amplitude of sticky costs in the entire region.

The study has many limitations: First to mention is the small size of the interview partners. The twelve interviews enabled insights that the author would have never expected. It seems that through serendipity the size is sufficient. All interviews were consistent concerning the core message: Sticky costs are a chore, but we are learning to deal with it.

\section{References}

1. Boadu, M., Sorour, M. K. (2015), "On utilizing grounded theory in business doctoral research: Guidance on the research design, procedures, and challenges", International Journal of Doctoral Studies, Vol. 10, pp. 143-166.

2. Cerovic, Lj., Drpic, D., Milojica, V. (2014), "The possibilities for repositioning of the Opatija Riviera's tourism offer", UTMS Journal of Economics, Vol. 5, No.1, pp. 121-130.

3. Charmaz, K. (1980), "The construction of self-pity in the chronically ill", Studies in Symbolic Interaction, Vol. 3, pp. 123-145.

4. Charmaz, K. (2008), "Grounded theory", in Smith, J. A. (Ed.), Qualitative psychology: A practical guide to research methods, Los Angeles sage Publications, pp. 81-110.

5. Cheung, J., Kim, H., Kim, S., Huang, R. (2018), "Is the asymmetric cost behavior affected by competition factors?", Asia-Pacific Journal of Accounting \& Economics, Vol. 25, No. 1-2, pp. 218-234.

6. Corbin, C. B. (1992), "The effects of verbal feedback on intrinsic motivation and perceived competence of cricketers", Australian Journal of Science and Medicine in Sport (AJSMS), Vol. 24, No. 4, pp. 94-99. 
7. Eisenhardt, K. M. (1989), "Building theories from Case Study Research", Academy of Management Review, Vol. 14, No.4, pp. 532-550.

8. Hall, S. (1992), "New Ethnicities", in Rattansi, A., Donald, J. (Eds.), Race, Culture and Difference, Sage Publications, pp. 252-259.

9. Hughes, J., Wood-Harper, T. (1999), "Systems development as a research act", Journal of Information Technology, Vol. 14, No. 1, pp. 83-94.

10. Jones, M., Alony, I. (2011), "Guiding the Use of Grounded Theory in Doctoral Studies An Example from the Australian Film Industry", International Journal of Doctoral Studies, Vol. 6, pp. 95-114.

11. Krol, C. (2017), "Time-Starved B2B Buyers: Move Towards Shorter, More Targeted Experiences", Demand Gen Report, pp. 1-12.

12. Martin, P. Y., Turner, B. A. (1986), "Grounded theory and organisational research", Journal of Applied Behavioural Science, Vol. 22, No. 2, pp. 141-157.

13. Orlikowski, W. J. (1993), "CASE tools as organisational change: Investigating incremental and radical changes in systems development", MIS Quarterly, Vol. 17, No. 3, pp. 309340.

14. O'Hagan, A. O., O'Connor, R. (2015), "Towards an Understanding of Game Software Development Processes: A Case Study", in the Proceedings of the 22nd European Conference on Systems, Software and Services Process Improvement, Ankara, Turkey, Springer, pp. 3-16.

15. Slivar, I., Božić, S., Batković, A. (2016), "Innovation in Tourism: Perception of Tourism Providers from Croatia and Serbia", Review of Innovation and Competitiveness, Vol. 2, No. 4, pp. 37-56.

16. Sorros, J., Karagiorgos, A. (2013), "Understanding Sticky Costs and the Factors Affecting Cost Behavior", Working paper, University of Piraeus, Greece.

17. Strauss, A. L, Corbin, J., (1998), "Basics of Qualitative Research: Techniques and Procedures for developing Grounded Theory", Sage Publications Ltd, London.

\section{About the author}

Wolfram Irsa, Dipl.-Ing., CIRM, CFPIM is a PhD student at the International Joint CrossBorder PhD Programme in International Economic Relations and Management at the $\mathrm{FH}$ Burgenland in Austria. He received his master's degree in industrial engineering and has extensive industrial experience in quality management, new product implementation, sourcing of suppliers, designing effective and efficient supply chains and to industrialize goods and services in the digital arena of Industry 4.0. Postgraduate studies in California enabled him an international career, which he wishes to prolong with a finalized $\mathrm{PhD}$ study. He presents at scientific international conferences. The author can be contacted at 1719001125@fh-burgenland.at. 